Supporting Information for

Molecular design of polyampholytes for vitrificationinduced preservation of three-dimensional cell constructs without using liquid nitrogen

Kazuaki Matsumura, Sho Hatakeyama, Toshiaki Naka, Hiroshi Ueda, Robin Rajan,

Daisuke Tanaka, and Suong Hyu Hyon 


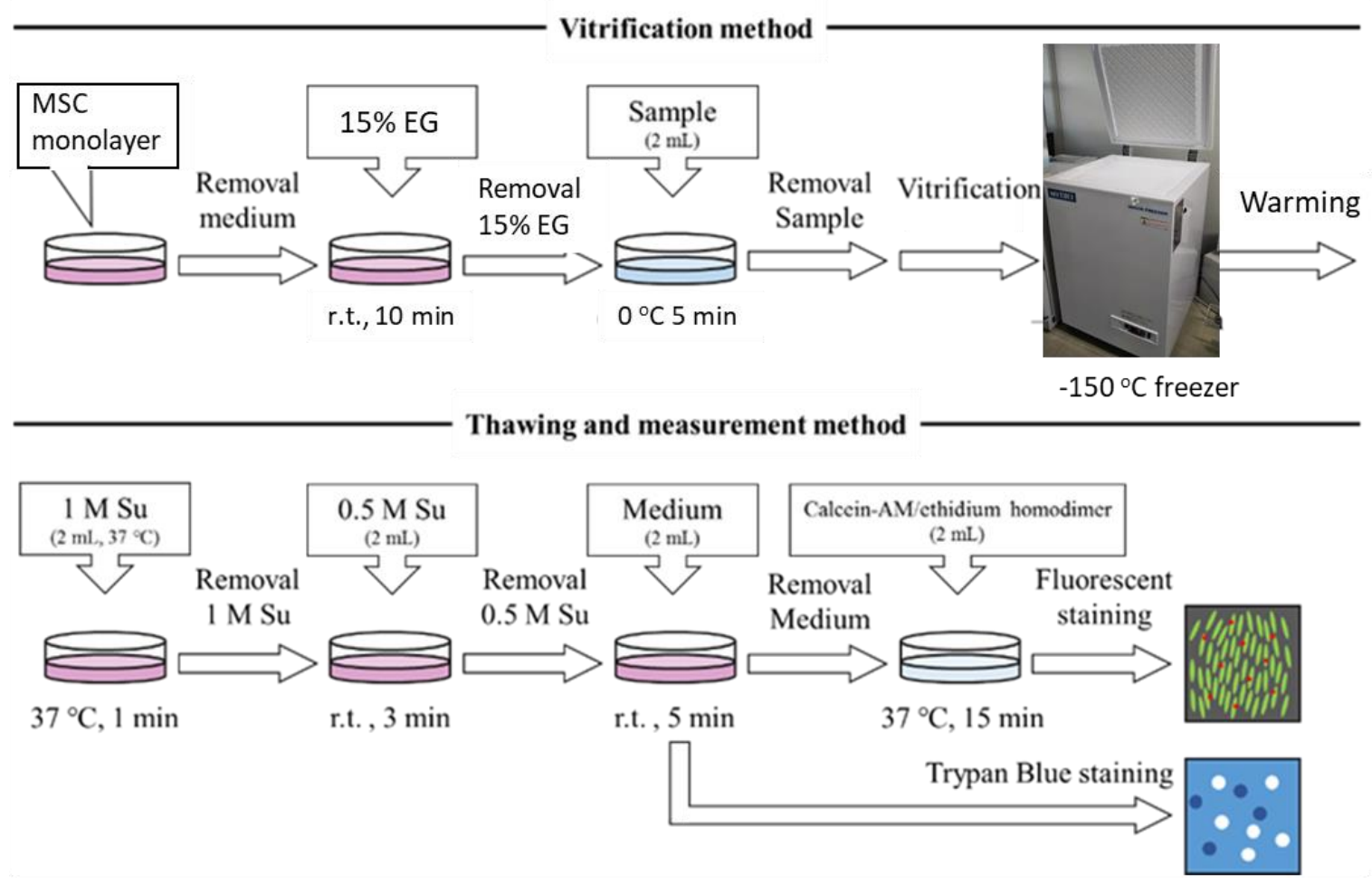

Scheme S1. Protocol for vitrification and warming of MSC monolayers using a freezer maintained at $-150{ }^{\circ} \mathrm{C}$. 
Vitrification method

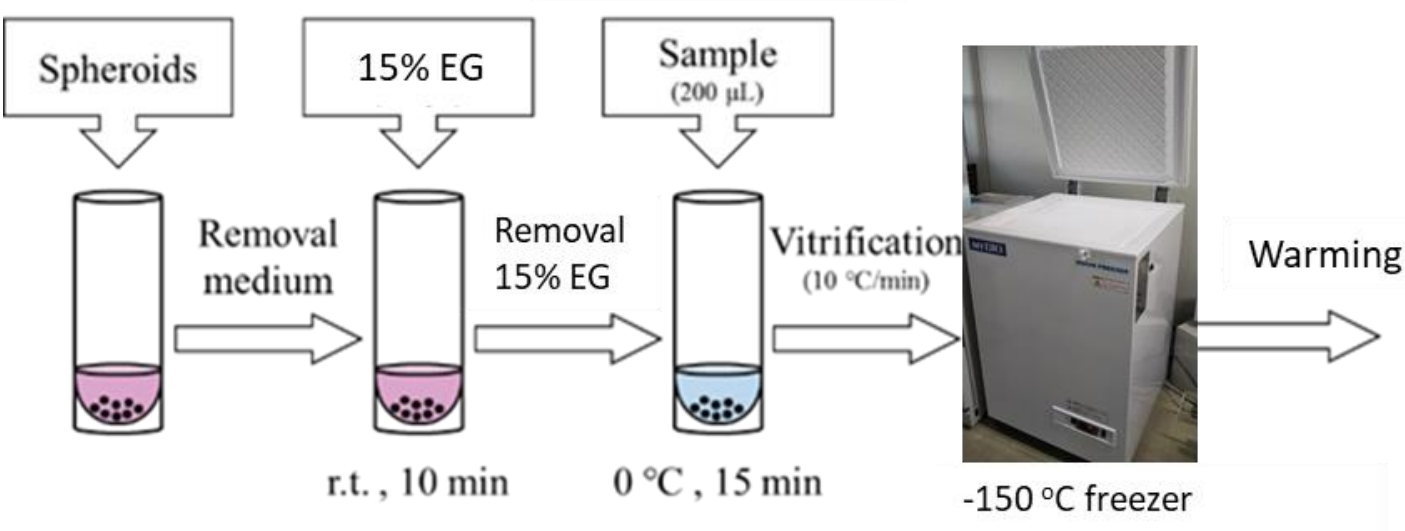

Thawing and measurement method

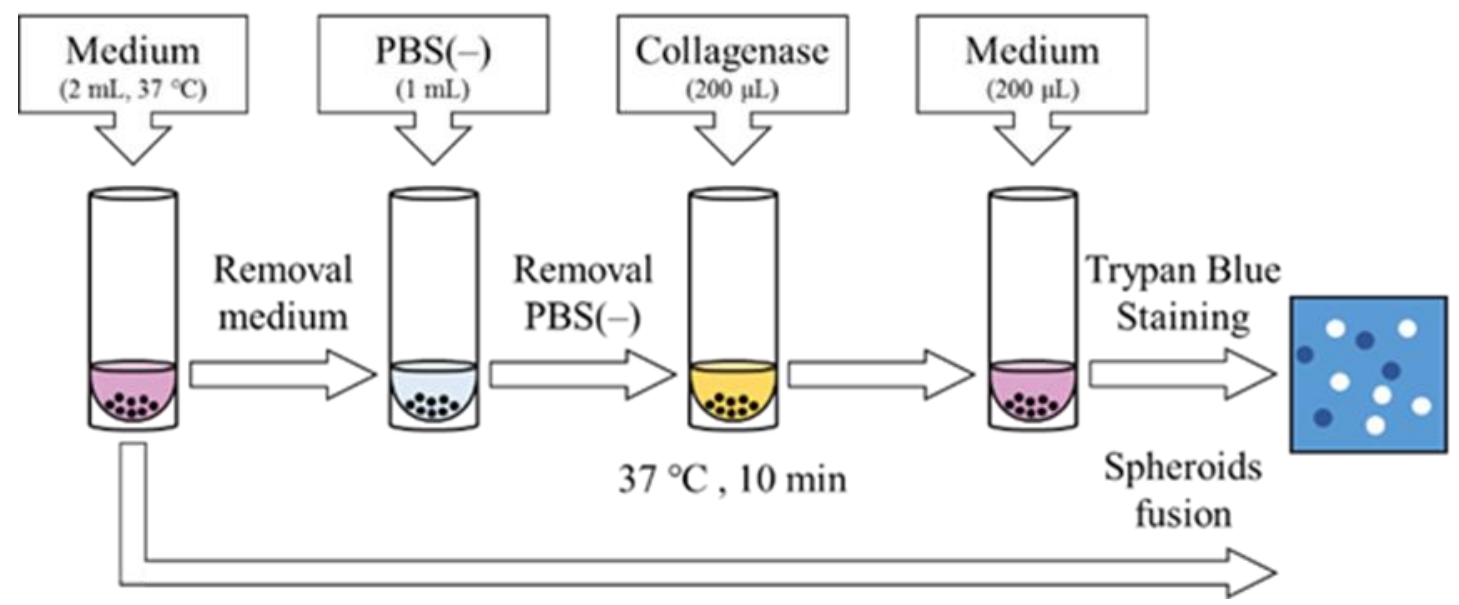

Scheme S2. Protocol for vitrification and warming of MSC spheroids using a freezer maintained at $-150^{\circ} \mathrm{C}$. 


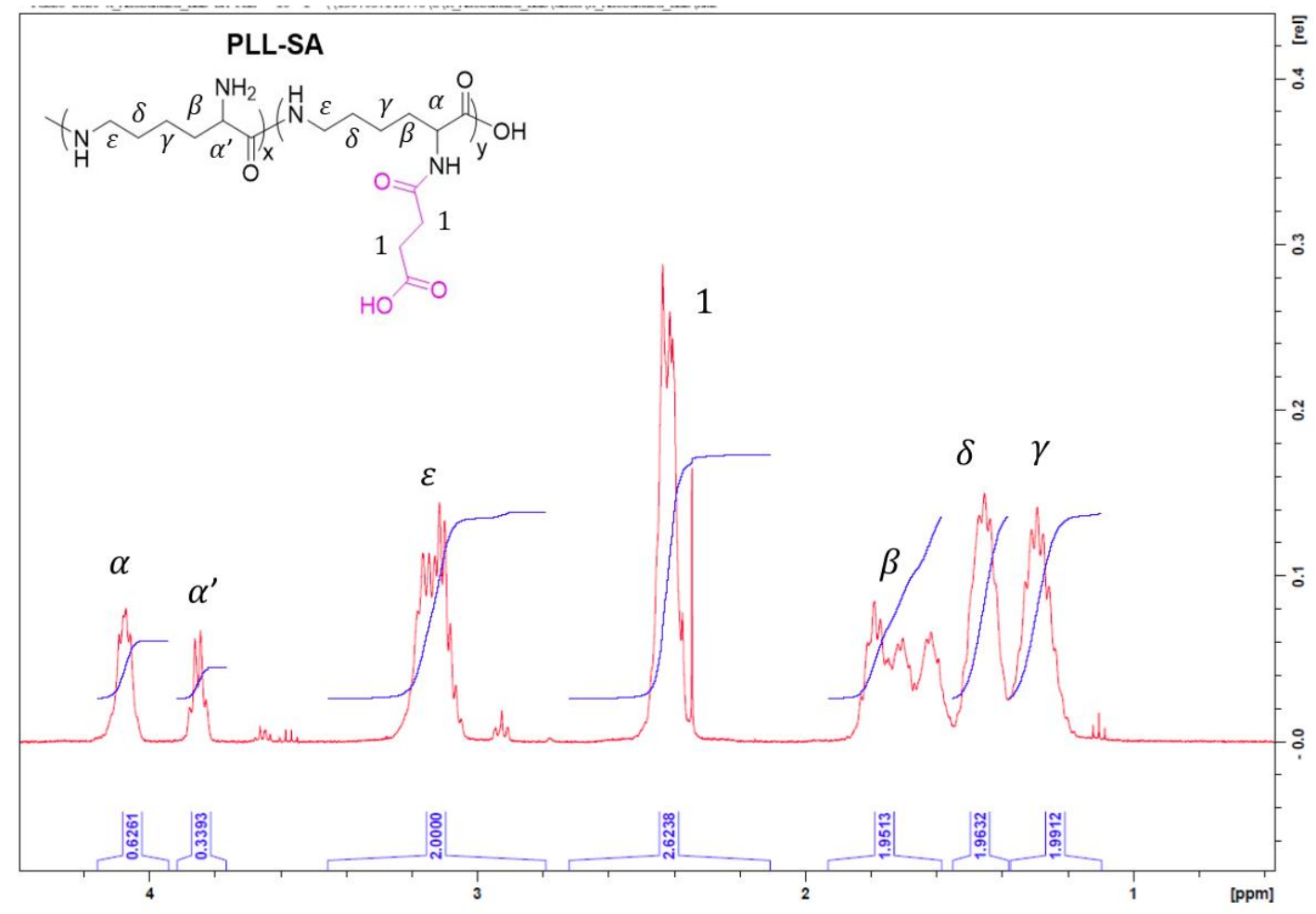

Figure S1. ${ }^{1} \mathrm{H}$ NMR spectrum of PLL-SA, obtained on a Bruker AVANCE III 400$\mathrm{MHz}$ spectrometer (Bruker Biospin, Switzerland). 


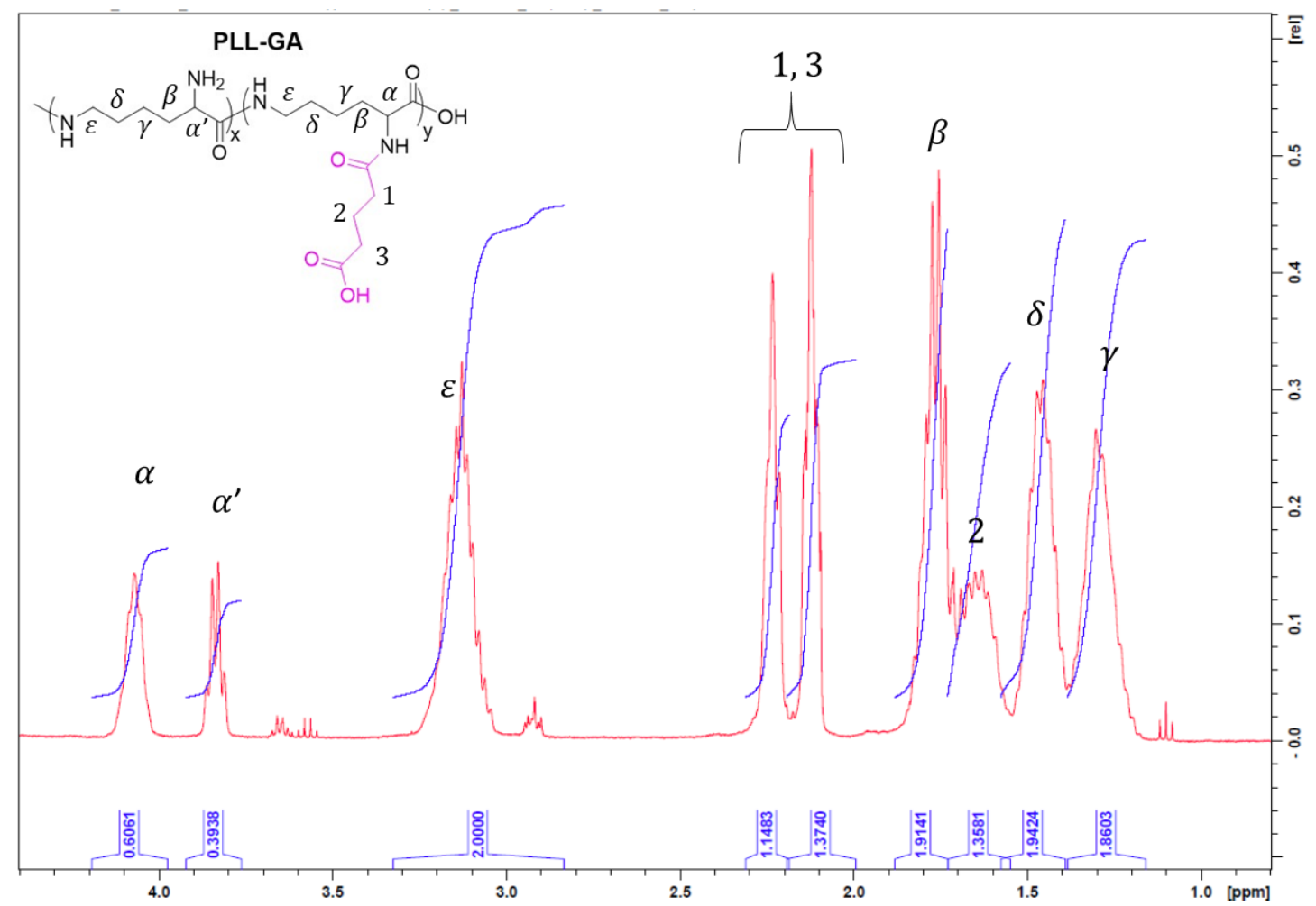

Figure S2. ${ }^{1} \mathrm{H}$ NMR spectrum of PLL-GA, obtained on a Bruker AVANCE III 400$\mathrm{MHz}$ spectrometer (Bruker Biospin, Switzerland). 


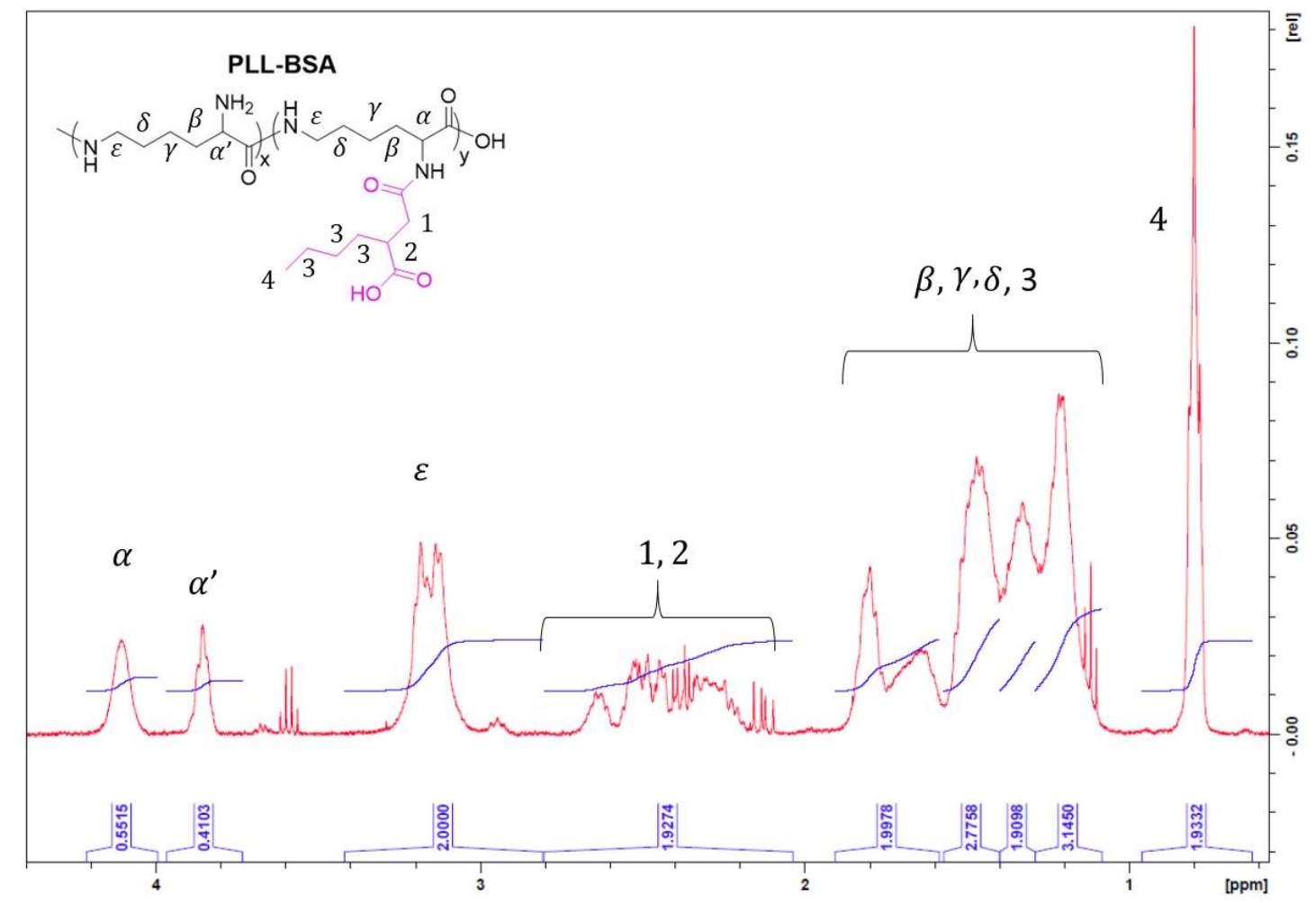

Figure S3. ${ }^{1} \mathrm{H}$ NMR spectrum of PLL-BSA, obtained on a Bruker AVANCE III 400$\mathrm{MHz}$ spectrometer (Bruker Biospin, Switzerland). 


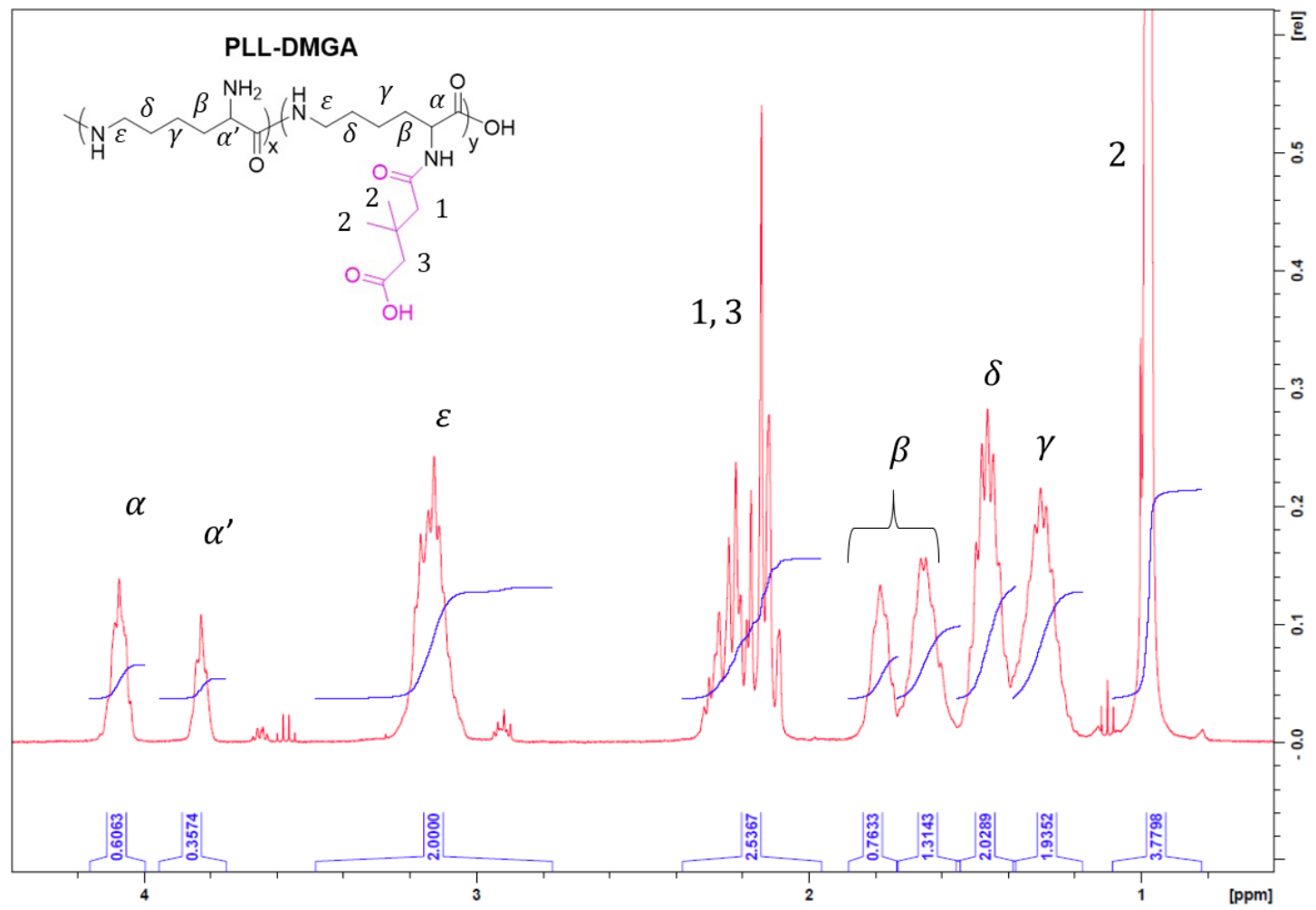

Figure S4. ${ }^{1} \mathrm{H}$ NMR spectrum of PLL-DMGA, obtained on a Bruker AVANCE III 400-MHz spectrometer (Bruker Biospin, Switzerland). 
Table S1. Viscosities of various VSs.

\begin{tabular}{|l|l|}
\hline VS & Viscosity / mPa·s \\
\hline EG6 & $32.7 \pm 2.3$ \\
\hline SA-EG6 & $265.7 \pm 6.6$ \\
\hline GA-EG6 & $295.4 \pm 11.3$ \\
\hline BSA-EG6 & $383.6 \pm 12.8$ \\
\hline DMGA-EG6 & $316.6 \pm 8.6$ \\
\hline PEG-EG6 & $280.0 \pm 6.1$ \\
\hline
\end{tabular}




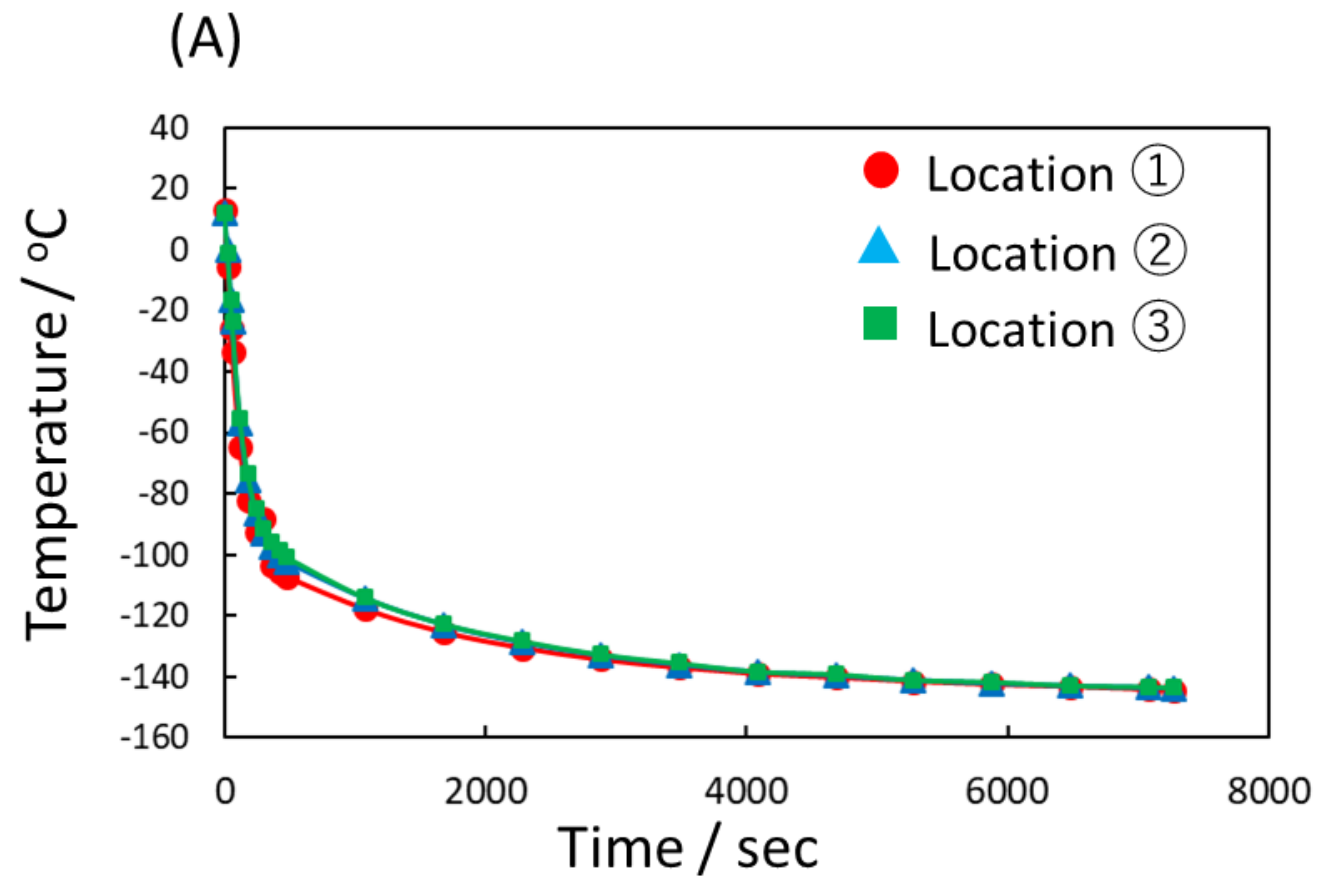

(B)

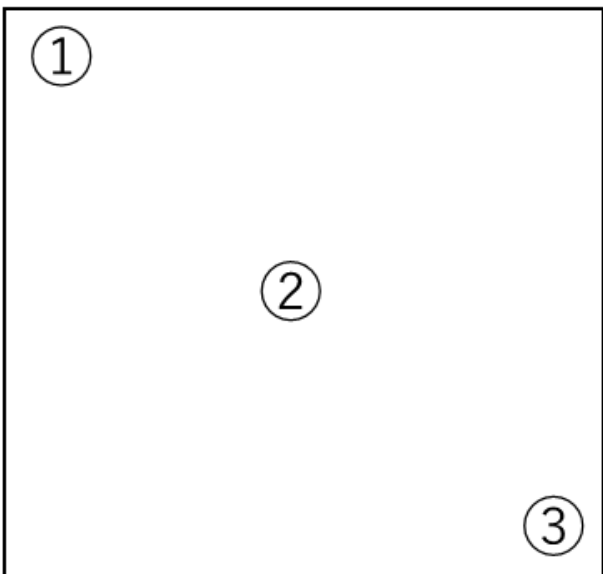

\section{Location in $-150{ }^{\circ} \mathrm{C}$ freezer}

Figure S5. (A) Temperature behaviors at three different locations in the freezer maintained at $-150{ }^{\circ} \mathrm{C}$. The thermostat positions are shown in (B). 


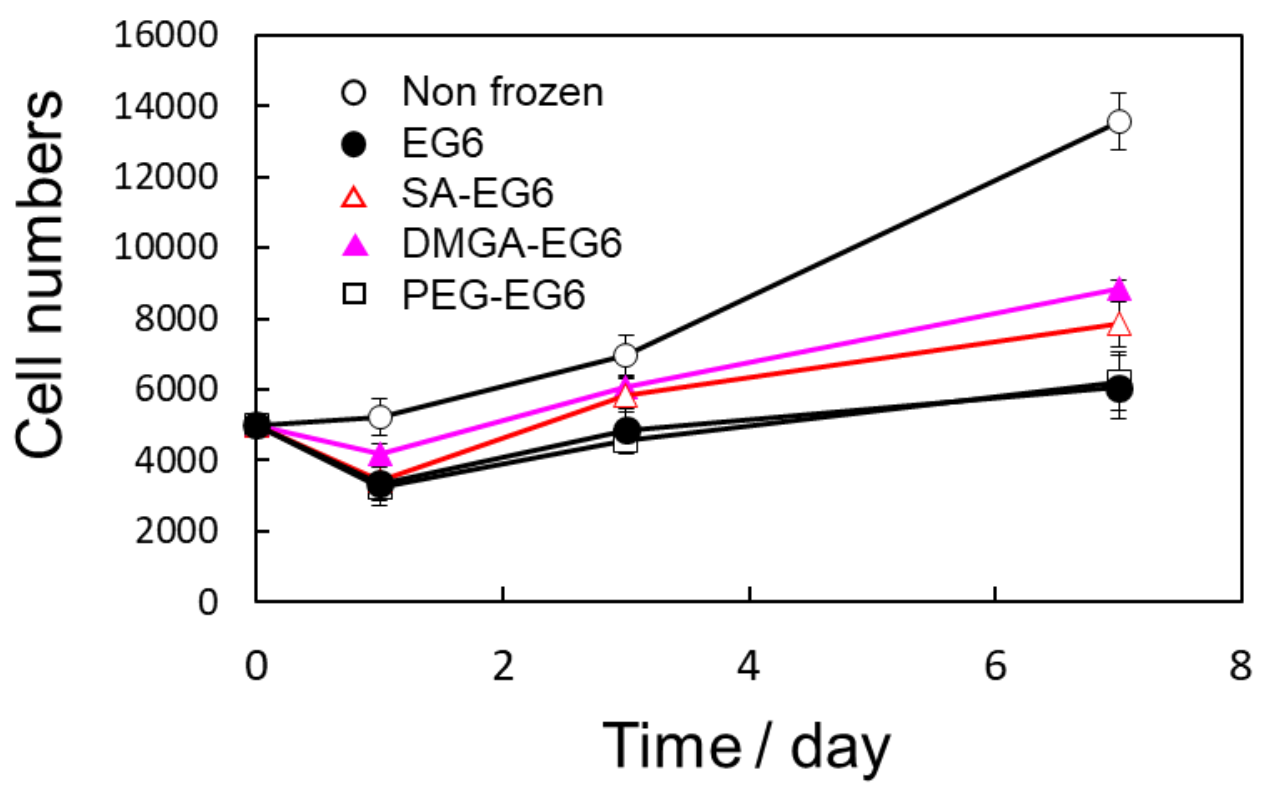

Figure S6. Cell proliferation curves for spheroids vitrified at $-150{ }^{\circ} \mathrm{C}$ using various vitrification solutions. 

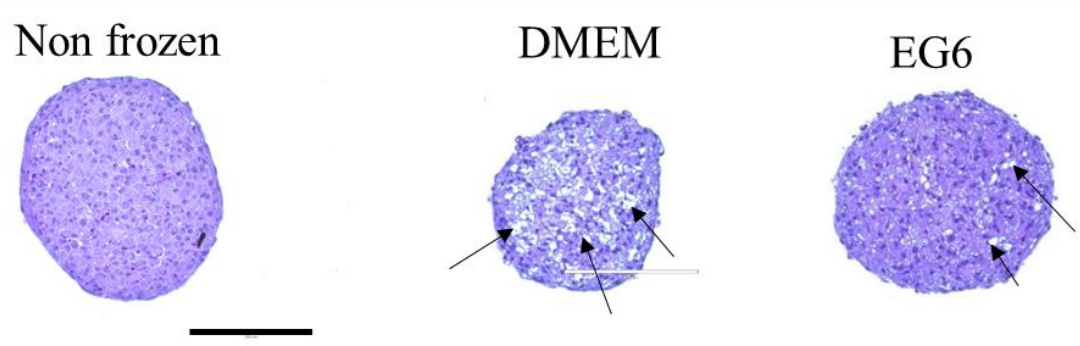

SA-EG5

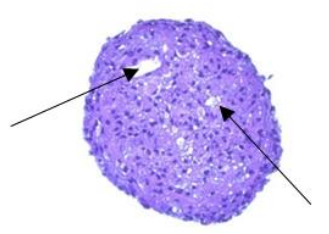

DMGA-EG5

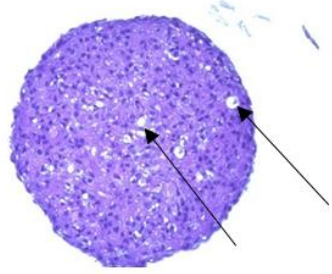

SA-EG6

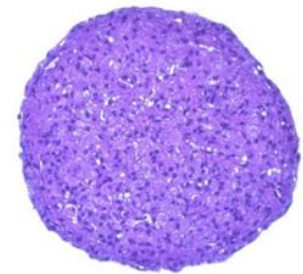

DMGA-EG6

\section{PEG-EG6}

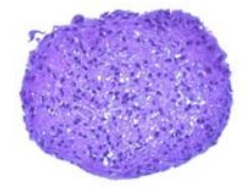

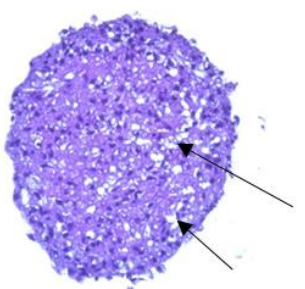

Figure S7. HE staining of spheroids vitrified using various VSs. Scale bar: 250 $\mu \mathrm{m}$.

The arrows represent the pores produced by ice crystallization during the vitrification process. 